\title{
A Bibliometric analysis of articles indexed in PubMed, 1988-2012, with Bahrain as first author affiliation
}

\section{Bruce M Manzer \\ bmanzerprc@gmail.com}

A review of the literature of bibliometrics as it relates to the Middle East turns up a number of studies and a few articles deploring the paucity of such studies. ${ }^{1-7}$ It will also show that, while there have been studies relating to the region as a whole and a few individual countries, there have been no studies specifically relating to Bahrain. It is as an effort to remedy this situation and to be a stimulus to others that this article appears.

PubMed has included the affiliation of first authors as a searchable field since 1988. It is thus possible by searching both Bahrain* and Bahrein* to identify some 727 articles where the first author is associated with an institution in Bahrain. These articles have been tabulated in an Excel table of authors, titles, affiliations, citations and subject classification (using the National Library of Medicine (NLM) classification system). An analysis of these articles covering the 25-year period from 1988 through 2012 was then undertaken to determine:

- The number of articles per year (Table 1),

- The authorship characteristics of these articles (i.e., number of authors per article and the number of unique authors) (Tables 2 and 3),

- The affiliation of the authors cited (Table 4),

- The journals where these articles appeared (Table 5) and,

- The subject distribution of the articles cited (Table 6).

\section{NUMBER OF ARTICLES PER YEAR AND THEIR AUTHORSHIP}

It can be seen that, while the general trend over the time period has been upward, it has been erratic. After a brief decline (2008-2010), however, there has been a distinct, sharp spurt.

Most of the 727 articles were authored by two writers (165), followed by those with three (143) and then four writers (130). Single authorship accounted for 118 articles. The range of number of authors was $1-13$, with a median of 6.5 .

Like the number of articles per year (Table 1) the general trend over the time period was upward but erratic, and again a retreat in 2007-2008, followed by a spurt upward from 2011 onward.

\section{AFFILIATION OF AUTHORS}

The bulk of the articles during the time period covered were, not surprisingly, produced by authors affiliated with four entities: the Arabian Gulf University, Salmaniya Medical Complex, the University of Bahrain, and the Ministry of Health.

\section{JOURNALS WHERE ARTICLES APPEARED}

Among the top five journals where articles were published, three are Saudi: Saudi medical journal, Annals of Saudi medicine, and the Saudi journal of kidney diseases and transportation.

\section{SUBJECT DISTRIBUTION OF ARTICLES}

Among the Preclinical sciences, the most heavily represented subjects were:

- Pharmacology, Pharmacy \& Toxicology

- Biochemistry, Genetics \& Nutrition 
Table 1: Number of articles per year (1988-2012)

\begin{tabular}{cccc}
\hline Year & No. of Articles & Year & No. of Articles \\
\hline 1988 & 10 & 2001 & 32 \\
1989 & 12 & 2002 & 30 \\
1990 & 9 & 2003 & 40 \\
1991 & 10 & 2004 & 52 \\
1992 & 19 & 2005 & 47 \\
1993 & 12 & 2006 & 51 \\
1994 & 16 & 2007 & 47 \\
1995 & 14 & 2008 & 35 \\
1996 & 11 & 2009 & 45 \\
1997 & 16 & 2010 & 38 \\
1998 & 18 & 2011 & 52 \\
1999 & 21 & 2012 & 62 \\
2000 & 28 & Total & 727 \\
\hline
\end{tabular}

Table 2: Number and percentage of articles per author groupings (1988-2012)

\begin{tabular}{ccc}
\hline No. of Authors & No. of Articles & Percent of Articles \\
\hline 1 & 118 & 16.23 \\
2 & 165 & 22.70 \\
3 & 143 & 19.67 \\
4 & 130 & 17.88 \\
5 & 77 & 10.59 \\
6 & 42 & 5.78 \\
7 & 26 & 3.58 \\
8 & 9 & 1.24 \\
9 & 5 & 0.69 \\
10 & 6 & 0.83 \\
11 & 5 & 0.69 \\
13 & 1 & 0.14 \\
\hline
\end{tabular}

Table 3: Number of unique authors per year (1988-2012)

\begin{tabular}{cccccc}
\hline Year & Unique authors & Year & Unique authors & Years & Unique authors \\
\hline 1988 & 22 & 1997 & 36 & 2006 & 131 \\
1989 & 30 & 1998 & 58 & 2007 & 120 \\
1990 & 19 & 1999 & 61 & 2008 & 94 \\
1991 & 20 & 2000 & 48 & 2009 & 121 \\
1992 & 41 & 2001 & 86 & 2010 & 114 \\
1993 & 20 & 2002 & 77 & 2011 & 163 \\
1994 & 43 & 2003 & 101 & 2012 & 183 \\
1995 & 29 & 2004 & 119 & & \\
1996 & 35 & 2005 & 122 & & \\
\hline
\end{tabular}


Table 4: Overview of author affiliation (1988-2012) for those with two or more citations

\begin{tabular}{lclc}
\hline Institution & Number & Institution & Number \\
\hline Arabian Gulf University & 234 & Al Khalifa Cardiac Center & 7 \\
Salmaniya Medical Complex & 209 & Bahrain Specialist Hospital & 7 \\
University of Bahrain & 51 & Roayl Medical Services [Hospital] & 7 \\
Ministry of Health & 46 & Al-Areen Wildlife Park & 3 \\
Bahrain Center for Studies \& Health & 26 & AMA-College of Medicine & 3 \\
Bahrain Defence Force & 22 & American Mission Hospital & 3 \\
Psychiatric Hospital & 20 & Gulf Air (Bahrain) & 3 \\
Al-Jawhara Center & 16 & KIMS & 3 \\
College of Health Sciences & 16 & BHIC & 2 \\
Bahrain Branch of the UK Cochrane Center & 15 & Bahrain Polytechnic & 2 \\
Royal College of Surgeons in Ireland & 15 & United States Navy & 2 \\
\hline
\end{tabular}

*The remaining citations all have one article in the time period covered; those interested can obtain this list from the writer. Affiliation has been aggregated within institutions. A breakdown is also available from the writer.

N.B.:There is a certain degree of ambiguity here in that some authors have joint affiliations

Table 5: Overview of journals where cited articles appeared (with 5 or more citations)

\begin{tabular}{lc}
\hline \multicolumn{1}{c}{ Journal } & No. of citations \\
\hline Saudi medical journal & 68 \\
Eastern Mediterranean Health Journal & 29 \\
Cochrane Database of Systematic Reviews (Online) & 28 \\
Annals of Saudi Medicine & 25 \\
Saudi Journal of Kidney Diseases and Transplantation & 17 \\
Journal of Laryngology and Otology & 13 \\
Medical Teacher & 13 \\
Education for health (Abingdon, England) & 8 \\
Nutrition and Health (Berkhamsted, Hertfordshire) & 8 \\
BMJ case reports & 7 \\
Translplantation proceedings & 7 \\
Clinical anatomy (New York, N.Y) & 6 \\
International Journal of Clinical Pharmacology and Therapeutics & 6 \\
Journal of evaluation in Clinical Practice & 6 \\
Journal of the Royal Society of Health & 6 \\
Journal of thrombosis and thrombolysis & 6 \\
Science of the total environment & 6 \\
Annals of human biology & 6 \\
Annals of throacic medicine & 5 \\
International Journal of Gynaecology and Obstestrics & 5 \\
Medical education & 5 \\
Medical principles and practice & 5 \\
\hline
\end{tabular}

*the reminder are one article only. Again, those interested can obtain the complete list from the writer 
- Microbiology \& Immunology

Among Medicine and Related Subjects the following topics are represented most:

- Urogenital system

-General medicine \& health professions

-Hemic \& lymphatic systems

-Musculoskeletal system

-Cardiovascular system

\section{OBSERVATIONS}

It is felt necessary to point out several incidental observations made during this analysis:

Authors should be consistent in the use of their names. A number of authors have permuted their names, romanized them inconsistently, and used them with varying degrees of completeness. One author's name appears in 11 different forms. This point is especially important for future indexing and searching purposes.

Further, titles should concisely reflect the contents of the article. "This works for us" is not a useful title for an article about "Therapy for pancreatic cysts in childhood;" nor is "The use of levofloxacin and ciprofloxacin as therapeutic adjuvants for the treatment of cystic fibrosis in a children's hospital in the southeastern part of Baluchistan: a cross-sectional study and review."

\section{CONCLUSION}

Bibliometrics has been recognized as a powerful tool in the armamentarium of quantitative research assessment. It provides answers to such questions as: what impact is our research having, in what subject area are we strongest and weakest, who is undertaking it, and at what institutions is it being conducted? The answers to these questions are vital to a nation's researchers and policy makers.

\section{References}

1. Aziz ABA, Khmakhem AM, Ghannem $\mathrm{H}$. Bibliometric profile of Tunisian medical publications indexed in Medline from 2000 to 2003: part 2 - social relevance. Tunisie Med. 2007;85(1):9-14.
2. Benamer HT, Bakoush O. Arab nations lagging behind other Middle Eastern countries in biomedical research: a comparative study. BMC Med Res Methodol. 2009;9:26.

3. Tadmouri NB, Tadmouri GO. Bibliometric analyses of biomedical research outputs in Lebanon and the United Arab Emirates [1988-2007]. Saudi Med J. 2009;30(1):130-9.

4. Hayajneh WA, Hayajneh RA, Miqdady MS. A bibliometric analysis of PubMed-published Jordanian literature in the twentieth century. Jordan Med J. 2010;44(2):152-8.

5. Salem S. Bibliometric aspects of medical information in Arab countries. Bull Med Libr Assoc. 1990;78(4):339-44.

6. Tadmouri GO. Biomedical bibliometrics of a country with multiple identities: the case of Palestine. Ann Alquds Med. 2006;1(2):63-8.

7. Tadmouri GO, Bissar-Tadmouri N. Biomedical publications in an unstable region: the Arab world, 1988-2002. Lance. 2003;362(9397):1766. 
Table 6. Subject distribution of articles (1988-2012)

\section{SUBJECT DISTRIBUTION OF ARTICLES}

\begin{tabular}{|c|c|c|}
\hline \multicolumn{3}{|c|}{ PRECLINICAL SCIENCES } \\
\hline $\begin{array}{l}\text { NLM } \\
\text { Class }\end{array}$ & Subject & No. of Articles \\
\hline $\mathrm{QH}$ & NATURAL HISTORY; BIOLOGY & 3 \\
\hline QS & HUMAN ANATOMY & 11 \\
\hline QT & PHYSIOLOGY; PHYSICAL EDUCATION; DIET & 7 \\
\hline QU & BIOCHEMISTRY. GENETICS; NUTRITION & 34 \\
\hline QV & PHARMACOLOGY, PHARMACY; TOXICOLOGY & 41 \\
\hline QW & MICROBIOLOGY AND IMMUNOLOGY & 30 \\
\hline QX & PARASITOLOGY & 3 \\
\hline QY & CLINICAL PATHOLOGY & 2 \\
\hline QZ & PATHOLOGY & 16 \\
\hline & TOTAL PRECLINICAL SCIENCES & 147 \\
\hline \multicolumn{3}{|c|}{ MEDICINE AND RELATED SUBJECTS } \\
\hline $\mathrm{W}$ & GENERAL MEDICINE; HEALTH PROFESSIONS & 42 \\
\hline WA & PUBLIC HEALTH & 36 \\
\hline WB & PRACTICE OF MEDICINE & 17 \\
\hline $\mathrm{WC}$ & COMMUNICABLE DISEASES & 31 \\
\hline WD & DISORDERS OF SYSTEMIC, METABOLIC \& ENVIRONMENTAL ORIGIN & 29 \\
\hline WE & MUSCULOSKELETAL SYSTEM & 39 \\
\hline WF & RESPIRATORY SYSTEM & 12 \\
\hline WG & CARDIOVASCULAR SYSTEM & 38 \\
\hline WH & HEMIC \& LYMPHATIC SYSTEMS & 40 \\
\hline WI & GASTROINTESTINAL SYSTEM & 25 \\
\hline WJ & UROGENITAL SYSTEM & 50 \\
\hline WK & ENDOCRINE SYSTEM & 30 \\
\hline WL & NERVOUS SYSTEM & 21 \\
\hline WM & PSYCHIATRY & 22 \\
\hline $\mathrm{WN}$ & RADIOLOGY & 0 \\
\hline WO & SURGERY & 5 \\
\hline WP & GYNECOLOGY & 22 \\
\hline WQ & OBSTETRICS & 26 \\
\hline WR & DERMATOLOGY & 16 \\
\hline WS & PEDIATRICS & 21 \\
\hline WT & GERIATRICS; CHRONIC DISEASE & 6 \\
\hline WU & DENTISTRY; ORAL SURGERY & 13 \\
\hline WV & OTORHINOLARYNGOLOGY & 14 \\
\hline WW & OPHTHALMOLOGY & 10 \\
\hline WX & HOSPITALS \& OTHER HEALTH FACILITIES & 3 \\
\hline WY & NURSING & 6 \\
\hline WZ & HISTORY OF MEDICINE; WRITING \& PUBLISHING; OBITUARIES & 0 \\
\hline \multicolumn{2}{|r|}{$\begin{array}{l}\text { TOTAL MEDICINE AND RELATED SUBJECTS } \\
\end{array}$} & 574 \\
\hline \multirow[t]{2}{*}{ SF } & ANIMAL CULTURE; VETERINARY MEDICINE & 6 \\
\hline & GRAND TOTAL & 727 \\
\hline
\end{tabular}

